\section{Polymer-Assisted Solution-Phase Synthesis of Glycosyl Chlorides and Bromides Using a Supported Dialkylformamide as Catalyst}

\author{
Lourdes Encinas and Jose Luis Chiara* \\ Instituto de Química Orgánica General, CSIC; Juan de la \\ Cierva 3, E-28006 Madrid, Spain
}

Received February 8, 2008

Glycosyl halides are a very valuable and versatile group of synthetic intermediates widely used in carbohydrate chemistry for the ready functionalization at the anomeric carbon. Thus, glycosyl halides can be easily converted into $O$-glycosides, ${ }^{1} C$-glycosides, ${ }^{2-5}$ or glycals ${ }^{6}$ via the generation of intermediate anomeric carbocations, ${ }^{7}$ radicals, ${ }^{2}$ or cabanions. ${ }^{8}$ Because of their moderate stability, glycosyl halides possessing elaborate protecting group patterns are best prepared by introduction of the halide in the last step. A number of methods have been developed for this transformation starting from glycosyl esters, glycosyl hemiacetals, alkyl glycosides, glycosyl orthoesters, glycosyl acetals, glycals, and thio-, seleno-, or telluro-glycosides. ${ }^{9,10}$ However, the relatively harsh reaction conditions employed in many of these procedures often limit the use of acid-sensitive protecting groups in the starting carbohydrate substrate. With a combination of high reactivity with reasonable stability, glycosyl chlorides and bromides were the first, and for a long time practically the only, glycosyl donors used for the synthesis of complex $O$-glycosides in the presence of heavy metal salts (the Koenigs - Knorr reaction) ${ }^{11}$ or halide ions ${ }^{12}$ as promoters. Although important developments have been achieved in the preparation and activation of the highly stable glycosyl fluorides, ${ }^{13,14}$ and the highly reactive glycosyl iodides, ${ }^{15,16}$ the corresponding chlorides and bromides are still the most widely used glycosyl halides. Generation of these glycosyl donors under mild neutral conditions is possible using $\mathrm{Ph}_{3} \mathrm{P} / \mathrm{CX}_{4}(\mathrm{X}=\mathrm{Cl}, \mathrm{Br}),{ }^{17-19} p$-TsCl/DMAP ${ }^{20}$ haloenamines, ${ }^{21} n$-BuLi/ClPO $(\mathrm{OPh})_{2},{ }^{4}$ or triphosgene-pyridine. $^{22}$ In some cases, the synthesis of these glycosyl donors and the subsequent glycosylation reaction can be accomplished in a sequential one-pot manner, avoiding the isolation of the intermediate halide. ${ }^{23-26}$ However, purification of the glycosyl halide is usually necessary and frequently problematic. The use of solid-supported reagents opens an interesting perspective for the efficient preparation of these delicate compounds by greatly simplifying their isolation. Successful implementations of this kind of strategy have been recently achieved through the use of a polymer-supported triarylphosphine in the presence of $\mathrm{CBr}_{4}{ }^{26}$ or $\mathrm{I}_{2}{ }^{27}$ and by means of a polymer-supported haloenamine. ${ }^{28}$

In the context of a project aimed at the development of new methods for the efficient and high-throughput synthesis

* To whom correspondence should be addressed. E-mail: j1.chiara@ iqog.csic.es. of oligosaccharides, ${ }^{29}$ we decided to develop an alternative polymer-assisted solution-phase synthesis of glycosyl chlorides and bromides based on the widely used and high yielding anomeric halogenation of carbohydrate hemiacetals with oxalyl chloride or bromide catalyzed by $N, N$-dimethylformamide. In this well-known procedure, ${ }^{30-32}$ the $N, N$ dimethylformide is transformed in situ into the corresponding Vilsmeier salt, which is the actual halogenating reagent. The use of a polymer supported $N, N$-dialkylformamide as catalyst could streamline the isolation of the glycosyl halide product through simple filtration of the crude reaction mixture, followed by evaporation of the solvent and excess oxalyl reagent at reduced pressure. Two known polystyrenesupported dialkylformamides $\left(\mathbf{2}^{33,34}\right.$ and $\left.\mathbf{5}^{33}\right)$ were examined for this purpose (Scheme 1). Polymer-supported $N$-formylpiperazine $\mathbf{2}$ was prepared using a modification of the described procedure, ${ }^{34}$ by $\mathrm{N}$-acylation of commercially available piperazine resin 1 with ethyl formate under DMAP catalysis. Supported $\mathrm{N}, \mathrm{N}$-dialkylformamide $\mathbf{5}$ was obtained from crosslinked chloromethylated polystyrene (Merrifield resin, 3) by successive reaction with methylamine followed by $\mathrm{N}$ acylation of the resultant methylamine resin 4 with ethyl formate as above. The progress of these solid-phase reactions was monitored by FT-IR spectroscopy, ${ }^{35}$ and the final resin loadings were determined by nitrogen elemental analysis.

Initial experiments were performed using 2,3,4,6-tetra- $O$ benzyl-D-glucose (6a, Chart 1) as a test substrate and dichloromethane as solvent in the presence of the resin (2 or 5; 0.1-1.0 mol equiv) by dropwise addition of oxalyl chloride (3 mol equiv.) under mild magnetic stirring. When the reaction was judged complete by TLC monitoring, the mixture was filtered; the resin was thoroughly rinsed with $\mathrm{CH}_{2} \mathrm{Cl}_{2}$, and the solvent and excess oxalyl chloride were removed at reduced pressure. The crude product was analyzed by ${ }^{1} \mathrm{H}$ NMR, which showed that the corresponding glycosyl chloride was formed in very high yield and $>95 \%$ purity. In general, the crude product was somewhat cleaner with resin 5, and this resin was finally selected for further experiments. The reaction was reasonably fast $(2 \mathrm{~h})$ when a molar equivalent of $\mathbf{5}$ was used under room temperature conditions (Table 1, entry 1), although substoichiometric amounts of 5 ( $0.1-0.5$ mol equiv; entries 3 and 4$)$ could be employed without compromising the yields at the expense of increased reaction times $(4 \mathrm{~h})$. No reaction was observed in the absence of the resin. Compared to the homogeneous reaction using DMF as catalyst, which produces the thermodynamic product exclusively, the $\alpha$-glycosyl chloride, ${ }^{36}$ its supported analog 5 affords an $\alpha / \beta$ mixture of glycosyl chlorides 7a. As expected, lower temperatures produced increased amounts of the kinetic product, the $\beta$-glycosyl chloride (entry 2). Reduced amounts of resin have the same effect (entries 3 and 4), which supports the role of the dialkylformamide as a catalyst of the $\alpha / \beta$-isomerization process of the glycosyl halide, as recently reported. ${ }^{26}$ Several differently protected mono and disaccharide hemiacetals $(\mathbf{6 b}$, 
Scheme 1

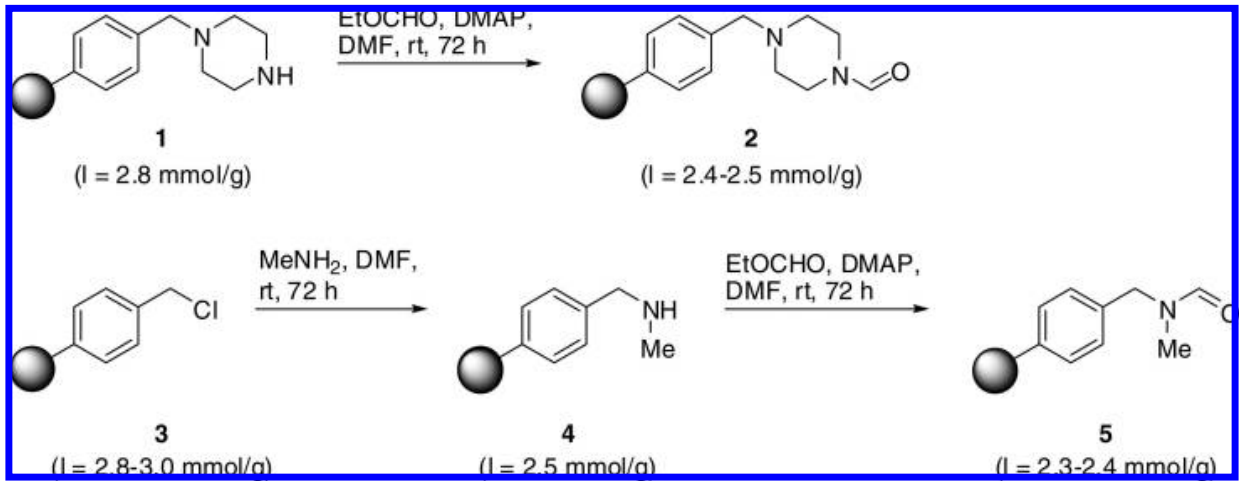

Chart 1

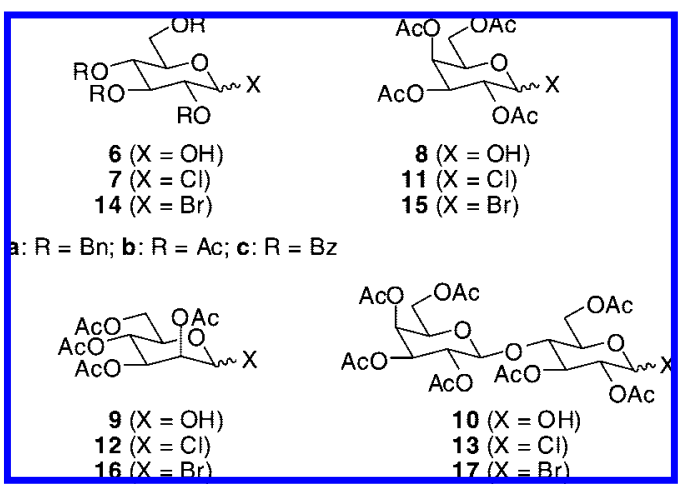

Table 1. Synthesis of Glycosyl Chlorides and Bromides by Reaction of Protected Sugar Hemiacetals with Oxalyl Chloride, Triphosgene, or Oxalyl Bromide in the Presence of Polymer-Supported Dialkylformide $\mathbf{5}$

\begin{tabular}{|c|c|c|c|c|c|c|c|}
\hline entry & substrate & $\begin{array}{l}\text { halogenating } \\
\text { reagent }\end{array}$ & $\begin{array}{l}\text { resin } \mathbf{5} \\
\text { (equiv) }\end{array}$ & $\begin{array}{l}\text { temp } \\
\left({ }^{\circ} \mathrm{C}\right)\end{array}$ & $\begin{array}{l}\text { time } \\
\text { (h) }\end{array}$ & product & $\begin{array}{c}\text { yield (\%) } \\
(\alpha / \beta \text { ratio })^{a}\end{array}$ \\
\hline 1 & $6 \mathbf{a}$ & $(\mathrm{COCl})_{2}^{b}$ & 1 & 20 & 2 & $7 \mathbf{a}$ & $98(66: 34)$ \\
\hline 2 & $6 a$ & $(\mathrm{COCl})_{2}{ }^{b}$ & 1 & 0 & 3 & $7 a$ & $93(34: 66)$ \\
\hline 3 & $6 a$ & $(\mathrm{COCl})_{2}^{b}$ & 0.5 & 20 & 4 & $7 a$ & $94(66: 34)$ \\
\hline 4 & $6 a$ & $(\mathrm{COCl})_{2}^{b}$ & 0.1 & 20 & 4 & $7 a$ & $97(58: 42)$ \\
\hline 5 & $6 a$ & $\left(\mathrm{Cl}_{3} \mathrm{CO}\right)_{2} \mathrm{CO}^{c}$ & 1 & 20 & 5 & $7 a$ & $99.9(66: 34)$ \\
\hline 6 & $6 \mathbf{a}$ & $(\mathrm{COBr})_{2}^{b}$ & 1 & 20 & 2 & $14 a$ & $98(>99: 1)$ \\
\hline 7 & $6 \mathbf{b}$ & $(\mathrm{COCl})_{2}{ }^{b}$ & 1 & 20 & 6 & $7 b$ & $90(5: 95)$ \\
\hline 8 & $6 \mathrm{~b}$ & $\left(\mathrm{Cl}_{3} \mathrm{CO}\right)_{2} \mathrm{CO}^{c}$ & 1 & 20 & 6 & $7 b$ & $98(3: 97)$ \\
\hline 9 & $6 \mathbf{b}$ & $(\mathrm{COBr})_{2}^{b}$ & 1 & 40 & 15 & $14 b$ & $90(>99: 1)$ \\
\hline 10 & $6 c$ & $(\mathrm{COCl})_{2}^{b}$ & 1 & 20 & 15 & $7 c$ & $91(<1: 99)$ \\
\hline 11 & $6 c$ & $\left(\mathrm{Cl}_{3} \mathrm{CO}\right)_{2} \mathrm{CO}^{b}$ & 1 & 20 & 6 & $7 c$ & $99.9(5: 95)$ \\
\hline 12 & $6 c$ & $(\mathrm{COBr})_{2}{ }^{b}$ & 1 & 40 & 5 & $14 c$ & $92(>99: 1)$ \\
\hline 13 & 8 & $(\mathrm{COCl})_{2}^{b}$ & 1 & 20 & 3 & 11 & $81(10: 90)$ \\
\hline 14 & 8 & $\left(\mathrm{Cl}_{3} \mathrm{CO}\right)_{2} \mathrm{CO}^{c}$ & 1 & 20 & 5 & 11 & $99(8: 92)$ \\
\hline 15 & 8 & $(\mathrm{COBr})_{2}{ }^{b}$ & 1 & 20 & 8 & 15 & $91(>99: 1)$ \\
\hline 16 & 9 & $(\mathrm{COCl})_{2}^{b}$ & 1 & 20 & 3 & 12 & $81(>99: 1)$ \\
\hline 17 & 9 & $\left(\mathrm{Cl}_{3} \mathrm{CO}\right)_{2} \mathrm{CO}^{c}$ & 1 & 20 & 5 & 12 & $93(>99: 1)$ \\
\hline 18 & 9 & $(\mathrm{COBr})_{2}^{b}$ & 1 & 20 & 9 & 16 & $80(>99: 1)$ \\
\hline 19 & 9 & $(\mathrm{COBr})_{2}{ }^{b}$ & 1 & 40 & 3 & 16 & $82(>99: 1)$ \\
\hline 20 & 10 & $(\mathrm{COCl})_{2}^{b}$ & 1 & 20 & 4.5 & 13 & $94(<1: 99)$ \\
\hline 21 & 10 & $\left(\mathrm{Cl}_{3} \mathrm{CO}\right)_{2} \mathrm{CO}^{d}$ & 1 & 20 & 6 & 13 & $98(5: 95)$ \\
\hline 22 & 10 & $(\mathrm{COBr})_{2}^{b}$ & 1 & 40 & 4.5 & 17 & $92(>99: 1)$ \\
\hline
\end{tabular}

${ }^{a}$ Determined by ${ }^{1} \mathrm{H}$ NMR. ${ }^{b} 3 \mathrm{~mol}$ equiv. ${ }^{c} 1 \mathrm{~mol}$ equiv. ${ }^{d} 2 \mathrm{~mol}$ equiv.

6c, 8-10) were reacted with oxalyl chloride in the presence of 5 under similar conditions (Table 1) to provide the corresponding glycosyl chlorides in excellent yields and purities without any purification. As expected, acyl substituted hemiacetals $(\mathbf{6 b}, \mathbf{6 c}, \mathbf{8}-\mathbf{1 0})$ react markedly slower than the corresponding benzylated analog $\mathbf{6 a}$, affording predominantly or exclusively the 1,2-trans-glycosyl chlorides. Resin 5 catalyzes also the reaction of oxalyl bromide with these substrates under similar conditions to provide the corresponding glycosyl bromides (Table 1, entries 6, 9, 12, 15, 18,19 , and 22). In general, the reactions are slower than in the case of oxalyl chloride, requiring reflux conditions in some cases. In contrast to their chloride analogs, the $\alpha$-glycosyl bromides are exclusively formed under these conditions.

We also tested triphosgene as a chlorinating reagent for the preparation of glycosyl chlorides from sugar hemiacetals in the presence of supported dialkylformamide $\mathbf{5}$ because triphosgene is known to react with dimethylformamide under mild conditions to generate the corresponding Vilsmeier salt. $^{34,37,38}$ Although triphosgene has been used before for the preparation of glycosyl chlorides in the presence of pyridine, ${ }^{22}$ its use for this purpose, using a dialkylformamide as promoter, has no precedent. In this case, the reactions were slightly slower than in the case of oxalyl chloride, but the products were formed in higher yields (93-100\%) and purities (>98\%) (Table 1, entries 5, 8, 11, 14, 17, and 21). As expected, the diastereoselectivities observed with triphosgene were approximately the same as those found with oxalyl chloride, since both reactions proceed through the same reactive intermediate.

Finally, we tested the recycling of the supported formamide because it acts just as a catalyst in the halogenation reaction. Resin 5 ( 1 mol equiv) could be reused in six successive reactions with hemiacetal 6a employing triphosgene as halogenating reagent without any loss of activity ( $>99 \%$ yield in each case). ${ }^{39}$

In conclusion, polystyrene-supported dialkylformamides are highly efficient catalysts for the solution-phase synthesis of glycosyl halides from sugar hemiacetals by reaction with oxalyl chloride, triphosgene, or oxalyl bromide, affording quantitative yields of pure products in short reaction times after simple filtration and evaporation.

Acknowledgment. We thank MEC for financial support (projects BQU2003-03550-C03-02 and CTQ2006-15515C02-02/BQU) and for a predoctoral fellowship to L.E.

Supporting Information Available. Detailed experimental procedures and characterization data for resin $\mathbf{2}$, resin $\mathbf{5}$, and the glycosyl halides, together with copies of the ${ }^{1} \mathrm{H}$ and ${ }^{13} \mathrm{C}$ NMR spectra of the crude glycosyl halides. This information is available free of charge via the Internet at http://pubs.acs.org. 


\section{References and Notes}

(1) Nitz, M.; Bundle, D. R. Glvcoscience 2001, 2, 1497-1542.

(2) Giese, B.; Dupuis, J. Angew. Chem.. Int. Ed. Engl. 1983, 22, 622-623.

(3) Hoffmann, M.; Kessler, H. Tetrahedron Lett. 1994, 35, 60676070.

(4) Hung, S.-C.; Wong, C.-H. Tetrahedron Lett. 1996, 37, 49034906.

(5) Gong, H.; Sinisi, R.; Gagne, M. R. J. Am. Chem. Soc. 2007, 129, 1908-1909.

(6) Priebe, W.; Grynkiewicz, G. Glvcoscience 2001, 1, 749-783.

(7) Garegg, P. J. Adv. Carbohvdr. Chem. Biochem. 2004, 59, 69134.

(8) Somsak, L. Chem. Rev. 2001, 101, 81-136.

(9) Lockhoff, O. Methoden der Organischen Chemie (HoubenWeyl); Georg Thieme Verlag: Stuttgart, Germany, 1992; Vol. E $14 \mathrm{a} / 3$.

(10) Gunn, S. J.; Warriner, S. L.; White, J. W. Sci. Sunth. 2007, 29, 889-922.

(11) Koenigs, W.; Knorr, E. Ber. Dtsch. Chem. Ges. 1901, 34, $957-$ 981.

(12) Lemieux, R. U.; Hendriks, K. B.; Stick, R. V.; James, K. J. Am. Chem. Soc. 1975, 97, 4056-4062.

(13) Yokoyama, M. Carbohvdr. Res. 2000, 327, 5-14.

(14) Toshima, K. Carbohvdr. Res. 2000, 327, 15-26.

(15) Gervay, J. Org. Svnth.: Theorv Appl. 1998, 4, 121-153.

(16) Kobashi, Y.; Mukaiyama, T. Chem. Lett. 2004, 33, 874-875.

(17) Ohrui, H.; Fox, J. J. Tetrahedron Lett. 1973, 14, 1951-1954.

(18) Grynkiewicz, G.; BeMiller, J. N. Carbohvdr. Res. 1984, 131 . 273-276.

(19) Ireland, R. E.; Thaisrivongs, S.; Vanier, N.; Wilcox, C. S. $\underline{J}$. Org. Chem. 1980, 45, 48-61.

(20) Hwang, C. K.; Li, W. S.; Nicolaou, K. C. Tetrahedron Lett. 1984, 25, 2295-2296.

(21) Ernst, B.; Winkler, T. Tetrahedron Lett. 1989, 30, 3081-3084.

(22) Cicchillo, R. M.; Norris, P. Carbohvdr. Res. 2000, 328, 431434.
(23) Khatuntseva, E. A.; Ustuzhanina, N. E.; Zatonskii, G. V.; Shashkov, A. S.; Usov, A. I.; Nifant'ev, N. E. J. Carbohvdr. Chem. 2000, 19, 1151-1173.

(24) Nishida, Y.; Shingu, Y.; Dohi, H.; Kobayashi, K. Org. Lett. 2003, 5, 2377-2380.

(25) Shingu, Y.; Nishida, Y.; Dohi, H.; Kobayashi, K. Org. Biomol. Chem. 2003, 1, 2518-2521.

(26) Shingu, Y.; Miyachi, A.; Miura, Y.; Kobayashi, K.; Nishida, Y. Carbohvdr. Res. 2005, 340, 2236-2244.

(27) Caputo, R.; Kunz, H.; Mastroianni, D.; Palumbo, G.; Pedatella, S.; Solla, F. Eur. J. Org. Chem. 1999, 3147-3150.

(28) Phillion, D. P. U.S. Patent Appl. WO 2003020684, 2003; Chem. Abstr. 2003, 138, 237798.

(29) Chiara, J. L.; Encinas, L.; Diaz, B. Tetrahedron Lett. 2005, 46, 2445-2448.

(30) Iversen, T.; Bundle, D. R. Carbohvdr. Res. 1982, 103, 29-40.

(31) Spohr, U.; Lemieux, R. U. Carbohydr. Res. 1988, 174, 211237.

(32) Pinto, B. M.; Reimer, K. B.; Morissette, D. G.; Bundle, D. R. J. Org. Chem. 1989, 54, 2650-2656.

(33) Ogawa, C.; Sugiura, M.; Kobayashi, S. Chem. Commun. 2003, 192-193.

(34) Rivero, I. A.; Espinoza, K. A.; Ochoa, A. J. Comb. Chem 2004, 6, 270-274.

(35) See the Supporting Information.

(36) Takeo, K.; Nakagen, M.; Teramoto, Y.; Nitta, Y. Carbohvdr. Res. 1990, 201, 261-275.

(37) Smith, D. C.; Lee, S. W.; Fuchs, P. L. J. Org. Chem. 1994, 59, 348-354.

(38) Li, P.; Xu, J. C. Tetrahedron Lett. 1999, 40, 3605-3608.

(39) However, independently of the halogenating reagent used, FTIR analysis of the resin beads after each use showed the appearance of new bands at $\sim 3480$ and $1730 \mathrm{~cm}^{-1}$, which cannot be ascribed to the intermediate Vilsmeier salt (see the Supporting Information). Although yields were always quantitative, the last runs required increased reaction times (7-12 h).

$\mathrm{CC} 800022 \mathrm{H}$ 